\title{
Norois
}

Environnement, aménagement, société

223 | 2012

Villes petites et moyennes

\section{Continents under Climate Change}

\section{Denis Mercier}

\section{(2) OpenEdition \\ Journals}

Édition électronique

URL : http://journals.openedition.org/norois/4241

DOI : 10.4000/norois.4241

ISBN : 978-2-7535-2043-1

ISSN : 1760-8546

Éditeur

Presses universitaires de Rennes

Édition imprimée

Date de publication : 30 mars 2012

Pagination : 123-124

ISBN : 978-2-7535-2041-7

ISSN : 0029-182X

Référence électronique

Denis Mercier, "Continents under Climate Change », Norois [En ligne], 223 | 2012, mis en ligne le 30 juin 2010, consulté le 26 avril 2019. URL : http://journals.openedition.org/norois/4241

(c) Tous droits réservés 

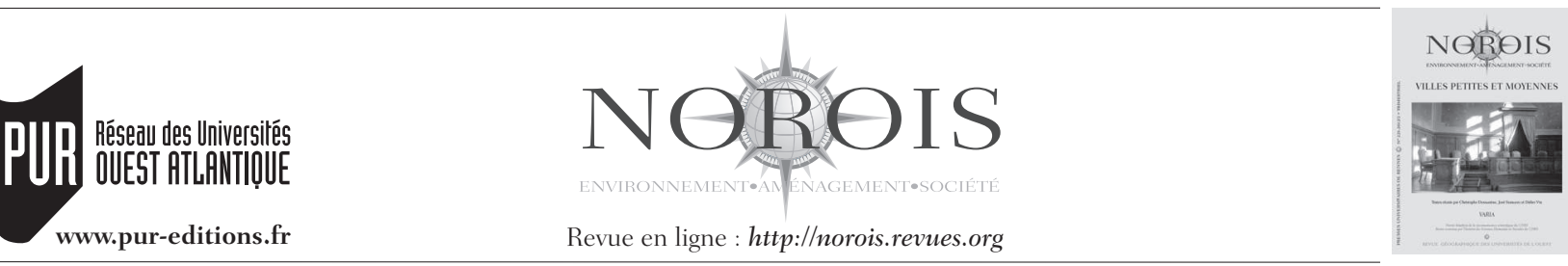

\section{COMPTE RENDU BIBLIOGRAPHIQUE}

Endlicher (Wilfried), Gerstengarbe (Friedrich Wilhelm) (eds.), 2010. - Continents under Climate Change, Nova Acta Leopoldina, Neue Folge, Nummer 384, Band 112, 317 p. ISBN 978-3-8047-2795-3.

Wilfried Endlicher et Friedrich-Wilhelm Gerstengarbe regroupent dans un numéro spécial les actes d'une conférence, tenue du 21 au 23 avril 2010, à l'occasion des 200 ans de la HumboldtUniversität de Berlin. Cette manifestation scientifique fut organisée avec la coopération du Potsdam Institute for Climate Impact Research (PIK) et l'Académie des Sciences allemande Leopoldina. Ce volume s'ouvre par une conférence introductive sur les pas d'Alexander von Humboldt et se compose de 25 articles, 103 figures et 17 tableaux. Il a pour ambition l'observation des changements climatiques selon les continents : l'Europe 8 contributions, les régions polaires 2, l'Afrique 6, l'Asie 3, l'Amérique 4 et l'Australie 2. Presque tous les articles ont été rédigés par des scientifiques allemands, ce qui illustre l'excellence de la recherche de nos collègues d'outre-Rhin. Les thématiques abordent les questions de l'adaptation au changement climatique, de la réponse des écosystèmes, des glaciers, du pergélisol, du cycle de l'eau, de l'élévation du niveau de la mer, de l'agriculture, des conflits d'usage des sols, des politiques, de la gouvernance, des stratégies, de la mortalité... le tout face au changement climatique.

Les textes, conformes à l'esprit du colloque, sont synthétiques. Certains graphiques, comme ceux illustrant la variabilité du climat au cours de l'Holocène, sont très intéressants et permettent de relativiser le rôle de l'Homme dans l'évolution du climat avant le XIX ${ }^{\mathrm{e}}$ siècle. On y voit notam-

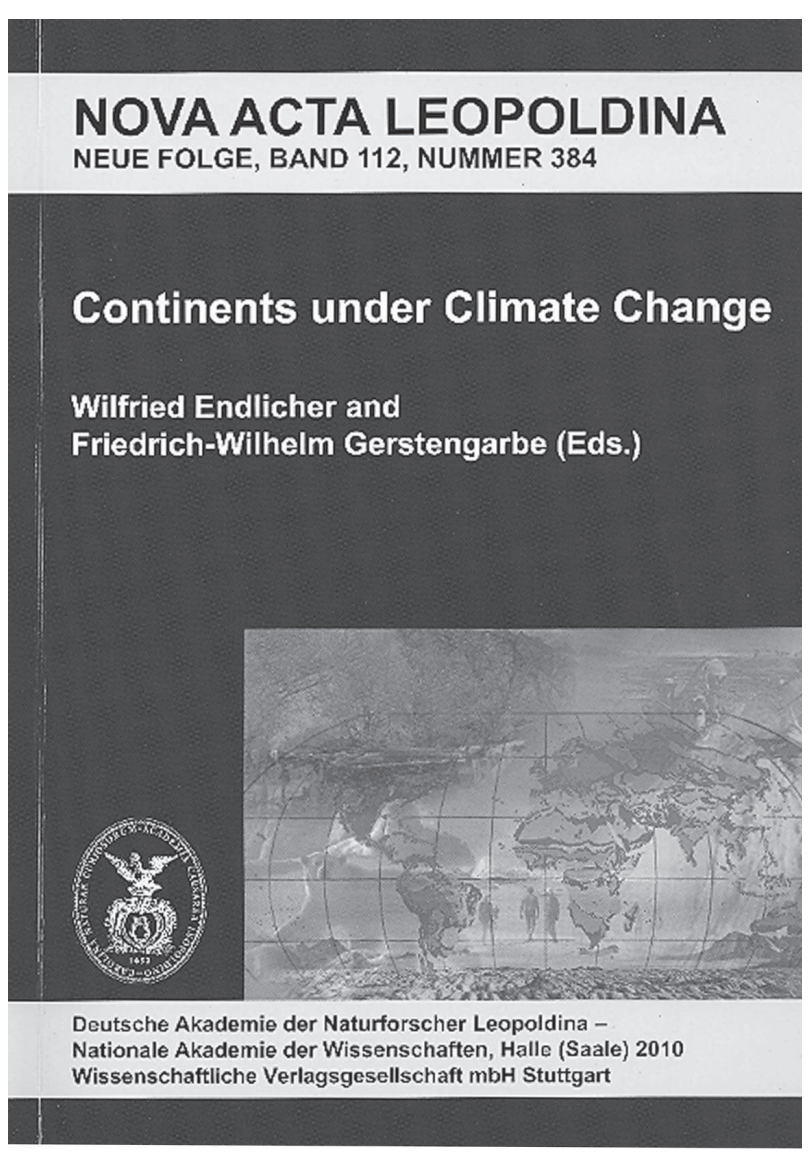

ment l'influence du forçage volcanique ainsi que la variabilité de l'irradiance solaire sur l'évolution des températures. La variabilité de l'activité solaire est responsable de la décroissance de 2 à $3{ }^{\circ} \mathrm{C}$ des 
températures moyennes de l'Europe avant la période industrielle. Des cartes de l'Europe d'ici 2070-2100 montrent par ailleurs la grande variabilité spatiale du réchauffement climatique envisagé, de même que les contrastes dans l'évolution de la répartition des précipitations. L'étude à l'échelle de l'Afrique méridionale depuis 1901, des relations statistiques entre la variabilité de l'énergie solaire (cycle de 11 ans) d'un côté et les températures, les précipitations et les pressions atmosphériques de l'autre, éclaire là encore, le rôle primordial de l'activité solaire sur la complexité de la machine climatique. Au-delà des études sur les éléments du réchauffement climatique, les approches sur les conséquences humaines et politiques de ce phénomène sont instructives. L'analyse des conflits d'usage entre bergers et agriculteurs en Afrique septentrionale et des vulnérabilités sociétales, comme conséquences des changements dans la répartition des régimes de précipitations et de la ressource en eau, présente une belle synthèse bibliographique des travaux récents sur ce thème, vital pour des centaines de millions d'habitants. L'article sur les impacts des changements thermiques et pluviométriques sur l'agriculture en Inde, et notamment sur la production de riz, montre tout l'intérêt des approches géographiques et la diversité des réponses locales à l'échelle de ce sous-continent. L'analyse des politiques urbaines et des concepts associés, comme les "compact cities ", montre l'importance des choix politiques face aux changements climatiques, notamment en Asie et en Amérique latine.

L'étude géographique du «global change » montre une fois de plus que les échelles spatiales et temporelles s'imposent à la réflexion et qu'une vision mondiale demeure souvent réductrice. En effet, tout l'intérêt de ce volume réside dans les études régionales, qui mettent en lumière les contrastes, tant dans le passé que pour les scénarios envisagés pour le siècle engagé, de même que la variabilité temporelle et spatiale du changement climatique et plus encore la complexité du système Terre. 